\title{
The Perceptual Span in Second Language Reading: An Eye-Tracking Study Using a Gaze-Contingent Moving Window Paradigm
}

\author{
Chi Yui Leung, Masatoshi Sugiura, Daisuke Abe, Lisa Yoshikawa \\ Graduate School of International Development, Nagoya University, Nagoya, Japan \\ Email: sieileung@nagoya-u.jp
}

Received 17 September 2014; revised 10 October 2014; accepted 5 November 2014

Copyright (C) 2014 by authors and Scientific Research Publishing Inc.

This work is licensed under the Creative Commons Attribution International License (CC BY). http://creativecommons.org/licenses/by/4.0/

cC) (i) Open Access

\section{Abstract}

The perceptual span, which is the visual area providing useful information to a reader during eye fixation, has been well investigated among native or first language (L1) readers, but not among second language (L2) readers. Our goal was to investigate the size of the perceptual span among Japanese university students who learn English as a foreign language (EFL) to investigate parafoveal processing during $\mathrm{L} 2$ reading. In an experiment using the gaze-contingent moving window paradigm, we compared perceptual span between Japanese EFL readers $(N=42)$ and native English $L 1$ readers $(N=14)$. Our results showed that $(1)$ the EFL readers had a smaller perceptual span than the $\mathrm{L} 1$ readers did, and (2) the facilitating effect of parafoveal information was greater for faster EFL readers than it was for slower EFL readers. These findings provide evidence that EFL readers can only utilize little parafoveal information during fixation when compared with L1 readers.

\section{Keywords}

EFL Readers, Eye Movements, Parafoveal Processing, Reading Speed

\section{Introduction}

During reading, our eyes can only utilize visual information from alimited sized visual area during a fixation. This area is called the perceptual span, which is approximately 3 - 4 characters to the left and 14 - 15 characters to the right of fixation among native English readers (Rayner, 1998, 2009). In the perceptual span, the visual area of highest acuity, the foveal area, normally captures only the currently fixated word $\left(2^{\circ}\right.$ in the center of vision), while a large proportion of the perceptual span falls into the parafoveal area, in which acuity is compara- 
tively lower (extending up to $5^{\circ}$ on both sides of fixation). Despite limited visual acuity, processing in parafoveal vision (i.e., parafoveal processing) is vital to fluent reading as it allows readers to preprocess visual information from upcoming words, facilitating subsequent word identification and saccade programming (Plummer \& Rayner, 2012; Rayner, 1998, 2009; Rayner, Liversedge, \& White, 2006). Nevertheless, the extent to which a reader can utilize parafoveal information in the perceptual span depends on attention and cognitive factors (Miellet, O’Donnell, \& Sereno, 2009; see Schotter, Angele, \& Rayner, 2012 for a review), which are closely related to text and task demands, as well as individual differences among readers.

\subsection{Factors Influencing the Perceptual Span}

For factors related to text and task demands, Henderson and Ferreira (1990) demonstrated that fixating on a more difficult word (e.g., a low-frequency word compared to a high-frequency word) imposed a greater processing load in the fovea, resulting in a decrease in attention allocated to the parafoveal word and thus a smaller perceptual span. Besides, the reading direction of the text is reported to influence the asymmetry of the perceptual span. As demonstrated by the study of Pollatsek, Bolozky, Well, and Rayner (1981) on the perceptual span of Hebrew readers. As Hebrew readers read from right to left, which is opposite to English, Hebrew readers pay more attention to the text left to fixation during reading, resulting in a perceptual span asymmetric to the left but not to the right. Recent studies by Jordan et al. (2014) and Paterson, McGowan, White, Malik, Adepidour, and Jordan (2014) investigating the perceptual spans during Arabic and Urdu reading, in which text is also printed from right to left, also reported similar findings. In addition, Schotter et al. (2012) pointed out that the size of the perceptual span is a function of average word length of the text and correspond to the number of words, not number of characters. These studies suggest that the perceptual span of a reader is not a constant but varies with what to be read.

For factors related to individual difference of readers, the perceptual spans of readers with less-developed reading skills, such as younger children, are smaller than are those of older children and adults, who are more skilled readers (Häikiö, Bertram, Hyönä, \& Niemi, 2009; Rayner, 1986). In addition, even among adult readers with fully developed reading skills, reading speed (Ashby, Yang, Evans, \& Rayner, 2012; Rayner, Slattery, \& Bélanger, 2010), reading comprehension and spelling skills (Veldre \& Andrews, 2014), as well as working memory (Osaka \& Osaka, 2002) have been reported as factors influencing perceptual span. These studies suggest that, even for the same text (see also Rayner et al., 2010), slower or less skilled readers devote more attentional resources to currently fixated words in the fovea compared to faster or skilled readers, leading to reduced attention for parafoveal processing and a smaller perceptual span.

Furthermore, reading strategy, which relates to both text and task demands, as well as reader attributes, is thought to influence the perceptual span. Rayner et al. (2009) suggested that older adult readers may rely more onprior contextbecause of poorer foveal and parafoveal processing, leading to a leftward shift in their perceptual span. Wotschack and Kliegl (2012) also reported that readers adjust their use of parafoveal information to the difficulty of the comprehension questions in a sentence-reading task. More attention is drawn to foveal words when comprehension questions are more difficult.

\subsection{The Gaze-Contingent Moving Window Paradigm}

The aforementioned studies investigating the perceptual span in reading mainly adopted the gaze-contingent display change technique, which synchronizes the display of stimuli on the computer screen with the fixation position of a participant's eye. One of the main paradigms making use of this technique is the gaze-contingent moving window (GCMW) paradigm (McConkie \& Rayner, 1975). In the GCMW paradigm, an area of text visible to participants on a computer screen, the window, moves according to participants' fixation position, with the text outside the window masked (see Figure 1). By manipulating the size of the window (in characters or words), the size of the perceptual span can be inferred when a larger window does not yield an increase in reading rate compared to a smaller window. However, while the GCMW paradigm or other gaze-contingent display change techniques have been widely adopted by studies in native or first language (L1) reading, they have rarely been used in second language (L2) studies.

\subsection{The Perceptual Span during L2 Reading}

For the perceptual span during L2 reading, three aforementioned studies_-Pollatsek et al. (1981), Jordan et al. (2014), 
Text

The beautiful girl wants to apply to go to a junior college.

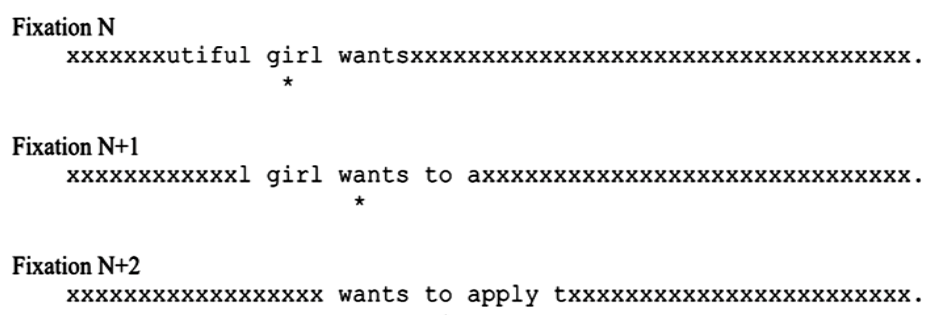

Figure 1. An example of how a symmetrical window with 17 visible characters (8 characters to both the left and right of fixation) moves according to changes in fixation position, which is represented by the asterisk.

and Paterson et al. (2014)—not only investigated the perceptual spans during L1 reading among native Hebrew, Arabic, and Urdu readers with the use of the GCMW paradigm, but also the perceptual spans when reading L2-English sentences. Although the primary focus of these studies were on the asymmetry of the perceptual span when reading text printed from right to left, the findings with respect to the L2-English reading tasks had important implications for the perceptual span during L2 reading.

First, all of the participants, as pointed out earlier, had a perceptual span asymmetric to the left in native reading, but showed a rightward asymmetry when reading L2-English, which are the same as the native English readers. These show that the perceptual span during L1 reading is primarily influenced by attention drawn to the direction in which the next saccade is planned, and the perceptual span during L1 reading does not change the asymmetry of the perceptual span during $\mathrm{L} 2$ reading.

Second, for the size of the perceptual span, as revealed by Pollatsek et al. (1981), L2 readers made shorter forward saccades than did native English readers. As forward saccade length can be considered an estimate of perceptual span size (see Whitford, O’Driscoll, Pack, Joober, Malla, \& Titone, 2013), it may imply that the perceptual span during L2 reading is smaller than it is during L1 reading. In addition, in the GCMW study by Paterson et al. (2014), the results on reading rates showed a smaller perceptual span during L2-English reading when compared to the L1-English readers reported in previous studies.

From the perspective of second language acquisition literature, it is logical to speculate that L2 readers have a smaller perceptual span compared to L1 readers. From the accounts based on foveal load (Henderson \& Ferreira, 1990), a lower level of automaticity in word recognition (Favreau \& Segalowitz, 1982) might incur higher processing costs and hence a smaller perceptual span during $\mathrm{L} 2$ reading.

However, it is noteworthy that these previous studies using the GCMW paradigm, such as Jordan et al. (2014), and Paterson et al. (2014) did not directly compare the size of the perceptual span between L1 and L2 readers. As indicated earlier, the perceptual span during reading is highly dependent on the characteristics of the text being read. Hence, direct comparison between L1 and L2 participant groups is important to contribute to our understanding of the perceptual span during L2 reading. Although Pollatsek et al. (1981) compared the eye movement data of their bilingual participants with the data of native English readers in similar experiments, the design of the GCMW paradigm for the bilingual participants did not allow detailed comparison in the size of the perceptual span between L1 and L2 readers.

Further, previous studies using the GCMW paradigm have only examined high-fluency L2 participants. As shown in the baseline conditions (i.e., no masking for text) in Pollatsek et al. (1981), Jordan et al. (2014), and Paterson et al. (2014), the average reading rates of the L2-English participants all exceeded 200 words per minute (WPM). In contrast, less fluent L2 readers, especially those who learn English as a foreign language (EFL), have been reported to have average reading rates from 80 to 130 WPM, far below 200 WPM (e.g., Hirai, 1999; Taguchi \& Gorsuch, 2002; Yamashita \& Ichikawa, 2010). At a reading rate below 200 WPM, Smith (1988: p. 79) argued that L1 readers tend to read sentences as "isolated units" of words and encounter difficulties in constructing the meaning of a sentence, while Dubin and Bycina (1991: p. 198) also argue that 200 WPM 
is a benchmark to divide readers who can read with full comprehension from those who cannot (see also Taguchi \& Gorsuch, 2002). Hence, together with the findings of previous studies that the perceptual span is a function of reading speed (Rayner et al., 2010) and L2 reading is more effortful (e.g., Favreau \& Segalowitz, 1982), the extent to which difference in perceptual span between L1 and EFL readers may be huge.

In a study using a self-paced reading task with a moving window in which the window moved according to when participants pressed a button, Yamashita and Ichikawa (2010) compared passage-reading rates among Japanese EFL readers with respect to different types of windows. Yamashita and Ichikawa (2010) found that the reading rates of less fluent EFL readers (mean reading rate $=85 \mathrm{WPM}$ ) were more indifferent to windows comprising multiple words relative to windows containing only one word when compared to more fluent EFL readers (mean reading rate $=133 \mathrm{WPM}$ ). Thus, it suggests that more fluent EFL readers may allocate more attention to parafoveal words during reading, implying that more fluent EFL readers may have a larger perceptual span.

However, as self-paced reading tasks may not truly reflect how language processing in natural reading (see Rayner, Pollatsek, Ashby, \& Clifton, 2012: p. 221; Roberts \& Siyanova-Chanturia, 2013), more empirical evidence, preferably with the use of eye-tracking and gaze-contingent display change techniques, is needed for the interpretations of the findings of Yamashita and Ichikawa (2010) with respect to parafoveal processing and the perceptual span during EFL reading.

\subsection{The Current Study}

Given the current state in the literature, there were two objectives for the present study. The first was to directly compare perceptual span size between EFL and L1-English readers when reading English sentences with the use of the GCMW paradigm. The second was to test what factors contribute to individual differences in the perceptual span among EFL readers. One consistent predictor for native readers reported in previous studies is reading speed (e.g., Ashby et al., 2012; Rayner, 1986; Veldre \& Andrews, 2014), which may account for differences in perceptual span among EFL readers (Yamashita \& Ichikawa, 2010).

We used a GCMW paradigm following the design of the first experiment of Rayner (1986), in which participants read sentences under with moving windows manipulated as follows (Figure 2): Sentences were divided into six conditions of which five contained symmetrical windows abbreviated as 5C, 11C, 17C, 23C, and 29C, as well as one baseline condition with no window (NW). The numbers in the abbreviations of the conditions represent the window size in number of visible characters (including interword spaces). For instance, in a 17C window size condition, a participant viewed eight characters both to the left and to the right of the fixation position. Each character that resided outside the given window was masked with an "x."

Using such a GCMW paradigm, Rayner (1986) found that while the reading rates of adult native English readers and older children continued to increase from the 5C to 29C conditions, they did not differ between the 29C and NW conditions, suggesting that their perceptual span extended up to 14 characters to the right of fixation. On the other hand, the reading rates of younger children stopped increasing at the 23C condition, indicating a smaller perceptual span than adults and older children. Based on previous findings, we predict that EFL readers

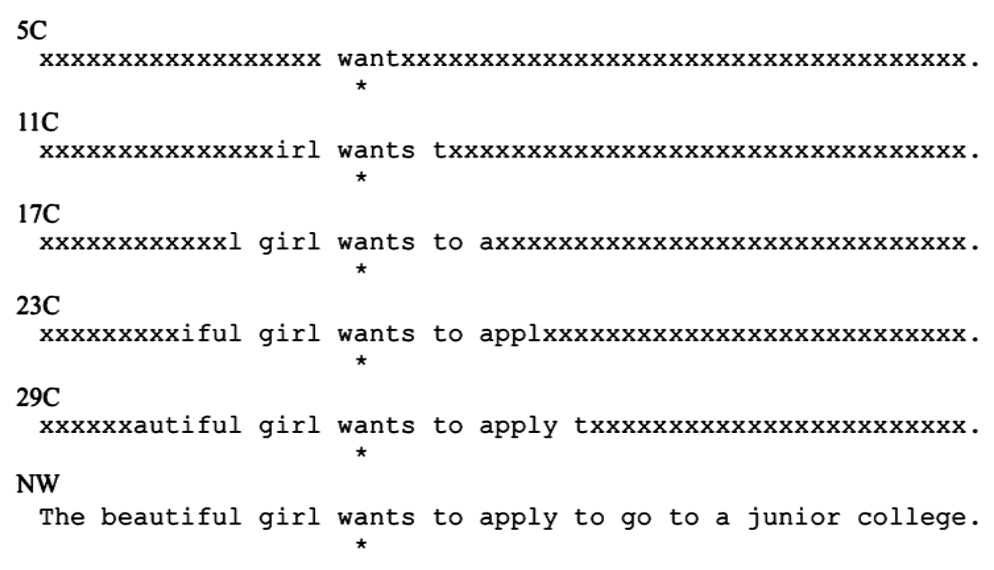

Figure 2. The moving window paradigm. The asterisk represents the fixation position. 
will have a smaller perceptual span than native English readers will, while the perceptual spans between faster and slower EFL readers should differ.

\section{Method}

\subsection{Participants}

Forty-two EFL readers (25 men and 17 women; mean age: 22.8) and 14 L1 readers (10 men and 4 women; mean age: 24.7) participated in the experiment. EFL readers were Japanese learners of English in Japan with a mean TOEFL score of $543.4(\mathrm{SD}=51.9)$. To examine the effect of reading speed on perceptual span, EFL participants were categorized into two groups-faster and slower EFL readers-using a median split for EFL readers' reading rates in the baseline condition. The background information of the individual EFL groups were summarized in Table 1. The L1 readers were all native English speakers from Australia, England, or the USA. All participants were undergraduate or graduate students at Nagoya University in Japan. They had normal or corrected-to-normal vision and received monetary compensation for their participation.

\subsection{Materials and Design}

Ninety-six English sentences were used. The average sentence length was 10.1 words (SD = 1.4; range: 8 - 13) and the average word length was 4.2 characters $(S D=0.6)$. All words used in the sentences were chosen from levels 1 - 2 of JACET List of Basic Words (JACET Committee of Basic Words Revision, 2003), which are comparable to the most basic 2000 English words. All sentences were easy to read, with a mean Flesch-Kincaid grade level of $4.8(\mathrm{SD}=2.5)$.

As indicated earlier, in the GCMW paradigm, there were six window size conditions (5C, 11C, 17C, 23C, 29C, and NW). Hence, six counterbalanced lists were created. Each participant read 16 sentences in each window size condition, and read each sentence once in only one of the window size conditions, while each sentence was presented in all window size conditions across participants. Sentence presentation was randomized.

\subsection{Apparatus and Procedure}

The right eye of each participant was tracked using EyeLink 1000 (SR Research Ltd.) at a sampling rate of 1000 $\mathrm{Hz}$ (viewing was binocular). Participants were seated in front of a 24-inch LCD monitor (BenQ XL2420T; refresh rate $=100 \mathrm{~Hz}$ ) with a chinrest at a viewing distance of approximately $66 \mathrm{~cm}$ from the monitor screen. One degree of visual angle equaled three characters.

A 9-point grid calibration was performed followed by a practice session (12 trials) and then the presentation of the experimental sentences. This ensured that participants were familiar with the GCMW paradigm. All sentences were displayed in black Courier New font on a white background as a single line on the screen. Participants were told to read the sentences silently, and press a button on a control pad immediately when finished. Half of the sentences were followed by a yes/no comprehension question. The mean accuracies for the comprehension questions for EFL and L1 groups were $89.5 \%$ and $96.7 \%$, respectively.

\section{Results}

Fixations with durations less than $80 \mathrm{~ms}$ or longer than $1000 \mathrm{~ms}$ were deleted (4.8\% of all fixations). Trials with

Table 1. Background information of each EFL participant group.

\begin{tabular}{|c|c|c|c|c|}
\hline & \multicolumn{2}{|c|}{ Slower EFL Readers } & \multicolumn{2}{|c|}{ Faster EFL Readers } \\
\hline & Mean & $S D$ & Mean & $S D$ \\
\hline Age & 21.5 & 1.9 & 23.9 & 2.7 \\
\hline Age of Onset & 11.6. & 1.5 & 11.0 & 2.1 \\
\hline TOEFL & 495.6 & 27.8 & 584.0 & 11.0 \\
\hline Reading Rate & 113.1 & 18.0 & 176.2 & 28.1 \\
\hline
\end{tabular}


a reading rate falling outside a \pm 2.5 SD range from the participant mean within a window size condition were removed (2.3\% of all trials).

The eye movement data for the EFL and L1 groups were then analyzed separately by linear mixed effects (LME) models (Baayen, Davidson, \& Bates, 2008) using R (R Development Core Team, 2013) and the lme4 package (Bates, Maechler, \& Bolker, 2012). Participants and items were treated as crossed random effects, including both random intercepts and slopes, although random slopes during model selection were removed when dropping the slopes did not result in a significant decrease in goodness-of-fit, checked by likelihood ratio tests (Baayen et al., 2008). For the fixed effects, window size was included in the LME models for both the EFL and the L1 readers, while reading speed and its interaction with window size were also entered into the models for the EFL readers.

Following previous studies in the literature, reading rate was used as the main measure to infer the size of the perceptual span in the GCMW paradigm. Besides, as the reading rate is a composite measure depending on fixation durations and saccades (Rayner, 1986), we also included forward saccade length, forward fixation duration and number of forward fixations into the analysis. Five successive difference contrasts (5C vs. 11C, 11C vs. 17C, $17 \mathrm{C}$ vs. $23 \mathrm{C}, 23 \mathrm{C}$ vs. $29 \mathrm{C}$, and $29 \mathrm{C}$ vs. NW) were set to examine the effect of incremental window size (Venables \& Ripley, 2002). Sum coding was used for reading speed (faster EFL readers vs. slower EFL readers). Regression coefficients $(b)$, standard errors $(S E)$, and $t$-values were reported. Fixed effects were treated as significant when $|t|>2$ (see Baayen, 2008). Conditional means for all measures are shown in Table 2.

\subsection{Reading Rate}

For the EFL readers, the effects of window size were significant for the $5 \mathrm{C}$ vs. $11 \mathrm{C}$ ( $b=52.60, S E=2.77, t=$

Table 2. Conditional means for reading rates and eye-movement measures.

\begin{tabular}{|c|c|c|c|c|c|c|c|}
\hline \multirow{2}{*}{ Measure } & \multirow{2}{*}{ Group } & \multicolumn{6}{|c|}{ Window Size } \\
\hline & & $5 \mathrm{C}$ & $11 \mathrm{C}$ & 17C & $23 \mathrm{C}$ & $29 \mathrm{C}$ & NW \\
\hline \multirow{4}{*}{ Reading Rate } & EFL Readers & $77(1.2)$ & $129(1.9)$ & $141(2.2)$ & $142(2.3)$ & $143(2.3)$ & $145(2.2)$ \\
\hline & Faster EFL Readers & $89(1.6)$ & $152(2.6)$ & 167 (2.9) & $167(2.9)$ & $172(3.1)$ & $176(2.9)$ \\
\hline & Slow EFL Readers & $64(1.4)$ & $106(2.2)$ & $115(2.5)$ & $113(2.4)$ & $114(2.4)$ & $113(2.2)$ \\
\hline & L1 Readers & $141(2.8)$ & $270(4.3)$ & $318(4.8)$ & $341(5.8)$ & $361(6.4)$ & $348(7.4)$ \\
\hline \multirow{4}{*}{ Forward Saccade Length } & EFL Readers & $3.5(0.043)$ & $4.5(0.036)$ & $5.0(0.040)$ & $5.2(0.043)$ & $5.2(0.043)$ & $5.2(0.045)$ \\
\hline & Faster EFL Readers & $3.7(0.075)$ & $4.7(0.053)$ & $5.2(0.060)$ & $5.4(0.060)$ & $5.5(0.063)$ & $5.4(0.061)$ \\
\hline & Slow EFL Readers & $3.3(0.039)$ & $4.3(0.045)$ & $4.8(0.051)$ & $4.9(0.057)$ & $5.0(0.056)$ & $4.9(0.063)$ \\
\hline & L1 Readers & $3.9(0.054)$ & $5.5(0.058)$ & $6.4(0.063)$ & $7.3(0.074)$ & $7.9(0.108)$ & $7.6(0.106)$ \\
\hline \multirow{4}{*}{$\begin{array}{l}\text { Average Fixation } \\
\text { Duration }\end{array}$} & EFL Readers & 321 (1.9) & $270(1.4)$ & $263(1.6)$ & $264(1.6)$ & $266(1.7)$ & $257(1.5)$ \\
\hline & Faster EFL Readers & $318(2.8)$ & $266(1.8)$ & $266(2.3)$ & $260(2.2)$ & $265(2.4)$ & $253(2.2)$ \\
\hline & Slow EFL Readers & $324(2.5)$ & $273(2.1)$ & $264(2.1)$ & $268(2.3)$ & 267 (2.3) & $261(2.1)$ \\
\hline & L1 Readers & $268(2.6)$ & $216(2.1)$ & 199 (1.9) & $201(2.1)$ & $200(2.1)$ & $197(2.1)$ \\
\hline \multirow{4}{*}{$\begin{array}{l}\text { Number of Forward } \\
\text { Fixations }\end{array}$} & EFL Readers & $18.4(0.27)$ & $14.0(0.20)$ & $13.0(0.19)$ & $12.8(0.20)$ & $12.5(0.19)$ & $12.8(0.20)$ \\
\hline & Faster EFL Readers & $15.8(0.29)$ & $12.0(0.21)$ & $10.9(0.18)$ & $10.6(0.18)$ & $10.1(0.18)$ & $10.4(0.18)$ \\
\hline & Slower EFL Readers & $21.0(0.39)$ & $16.0(0.31)$ & $15.0(0.28)$ & $15.0(0.33)$ & $14.9(0.29)$ & $15.2(0.32)$ \\
\hline & L1 Readers & $13.5(0.18)$ & $8.6(0.12)$ & $7.2(0.09)$ & $6.4(0.09)$ & $6.0(0.09)$ & $6.3(0.10)$ \\
\hline
\end{tabular}

Note: Standard errors are in parentheses. 
18.97) and 11C vs. 17C $(b=12.14, S E=1.95, t=6.22)$ contrasts, but not for the 17C vs. 23C $(b=-0.02, S E=2.17$, $t=-0.01), 23 \mathrm{C}$ vs. $29 \mathrm{C}(b=2.00, S E=2.38, t=0.84)$, or $29 \mathrm{C}$ vs. NW $(b=1.10, S E=1.84, t=0.60)$ contrasts,revealing overall higher reading rates with increasing window size up to the 17C window. Understandably, the effect of reading speed was significant $(b=-25.10, S E=3.18, t=-7.90)$, demonstrating that the faster EFL readers had higher reading rates than did slower EFL readers on average. The window size $\times$ reading speed interactions were significant for the $5 \mathrm{C}$ vs. $11 \mathrm{C}(b=-9.48, S E=2.55, t=-3.72)$ and $11 \mathrm{C}$ vs. 17C $(b=-3.83, S E$ $=1.80, t=-2.13)$ contrasts, but not for the 17C vs. 23C $(b=-0.96, S E=1.81, t=-0.53), 23 \mathrm{C}$ vs. 29C $(b=$ $-1.91, S E=2.06, t=-0.93)$, or $29 \mathrm{C}$ vs. NW $(b=-1.55, S E=1.83, t=-0.85)$ contrasts. Additional analyses for the faster and slower EFL readers revealed that both EFL groups read significantly faster in larger window sizes for the $5 \mathrm{C}$ vs. $11 \mathrm{C}$ (faster EFL readers: $b=62.25, S E=4.34, t=14.35$; slower EFL readers: $b=42.65, S E=$ 3.22, $t=13.23$ ) and $11 \mathrm{C}$ vs. $17 \mathrm{C}$ (faster EFL readers: $b=15.64, S E=2.97, t=5.27$; slower EFL readers: $b=$ 8.66, $S E=2.46, t=3.52$ ) contrasts, but neither group showed further increased reading rates for $17 \mathrm{C}$ vs. $23 \mathrm{C}$, $23 \mathrm{C}$ vs. 29C, and 29C vs. NW contrasts (all $|t s|<1$ ). These results indicate that while the reading rates for both the EFL groups reached asymptote at the 17C window, the increase in reading rates among faster EFL readers was larger than were those for slower EFL readers for the $5 \mathrm{C}$ vs. $11 \mathrm{C}$ and $11 \mathrm{C}$ vs. $17 \mathrm{C}$ contrasts.

For the L1 readers, the main effects of window size were significant for the 5C vs. $11 \mathrm{C}(b=127.45, S E=$ $8.42, t=15.13), 11 \mathrm{C}$ vs. $17 \mathrm{C}(b=49.48, S E=5.43, t=9.12), 17 \mathrm{C}$ vs. $23 \mathrm{C}(b=23.29, S E=7.69, t=3.03)$, and $23 \mathrm{C}$ vs. $29 \mathrm{C}(b=20.63, S E=5.87, t=3.51)$ contrasts, but not for the $29 \mathrm{C}$ vs. NW $(b=-14.68, S E=9.21, t=$ $-1.59)$ contrast, indicating that reading rates continued to increase with larger window size up to the 29C window.

\subsection{Forward Saccade Length}

For the EFL readers, the effects of window size were significant for the 5C vs. 11C $(b=0.96, S E=0.09, t=$ $10.73), 11 \mathrm{C}$ vs. $17 \mathrm{C}(b=0.49, S E=0.04, t=11.52)$ and the $17 \mathrm{C}$ vs. $23 \mathrm{C}(b=0.22, S E=0.04, t=5.30)$ contrasts, but not for the 23C vs. 29C ( $b=0.06, S E=0.04, t=1.49)$, or 29C vs. NW ( $b=-0.06, S E=0.05, t=$ $-1.10)$ contrasts. Similar to the results for reading rates, the effect of reading speed was significant $(b=-0.23$, $S E=0.11, t=-2.08)$. As opposed to reading rates, the window size $\times$ reading speed interactions were not significant for any contrast (all $|t s|<1.02$ ). These results indicate that forward saccade lengths continued to rise with increasing window size up to the 23C window for both EFL groups, with overall longer forward saccades for faster as opposed to slower EFL readers.

For L1 readers, significant main effects of window size indicating that forward saccade lengths continued to increase with larger windows were observed for the $5 \mathrm{C}$ vs. $11 \mathrm{C}(b=1.60, S E=0.11, t=14.76), 11 \mathrm{C}$ vs. $17 \mathrm{C}(b$ $=0.94, S E=0.13, t=7.42), 17 \mathrm{C}$ vs. 23C $(b=0.83, S E=0.10, t=8.06), 23 \mathrm{C}$ vs. $29 \mathrm{C}(b=0.62, S E=0.17, t=$ 3.62 ) contrasts, but not for the 29C vs. NW contrast $(b=-0.33, S E=0.12, t=-2.67)$.

\subsection{Forward Fixation Duration}

For L2 readers, the effects of window size were significant for the 5C vs. $11 \mathrm{C}(b=-51.43, S E=3.54, t=$ $-14.49), 11 \mathrm{C}$ vs. $17 \mathrm{C}(b=-5.88, S E=2.10, t=-2.80)$ and the $29 \mathrm{C}$ vs. NW $(b=-8.81, S E=2.34, t=-3.79)$ contrasts, but not for the 17C vs. 23C $(b=-0.11, S E=1.82, t=-0.06)$ or 23C vs. 29C $(b=2.58, S E=1.81, t=$ $1.42)$ contrasts. Neither the effect of reading speed $(b=2.72, S E=3.65, t=0.75)$ nor the window size $\times$ reading speed interactions were significant (all $|t \mathrm{~s}|<1.41$ ), indicating that decreases in forward fixation durations started to stop with increasing window size at the 17C window for both the L2 groups, while there was no difference in forward fixation durations between the two L2 groups.

For $\mathrm{L} 1$ readers, the main effects of window size were significant for the 5C vs. 11C $(b=-52.17, S E=4.59, t$ $=-11.37), 11 \mathrm{C}$ vs. $17 \mathrm{C}(b=-17.09, S E=2.98, t=-5.73)$ contrasts but not for the $17 \mathrm{C}$ vs. $23 \mathrm{C}(b=2.45, S E=$ 2.93, $t=0.83)$, 23C vs. 29C $(b=-1.53, S E=2.79, t=-0.55)$, or the 29C vs. NW $(b=-2.84, S E=2.88, t=$ $-0.99)$ contrast, indicating that forward fixation durations continued to drop with larger window size up to the 17C window.

\subsection{Number of Forward Fixations}

For the EFL readers, the effects of window size were significant for the 5C vs. $11 \mathrm{C}(b=-4.38, S E=0.42, t=$ 
$-10.42)$ and 11C vs. 17C $(b=-1.13, S E=0.22, t=-5.10)$ contrasts, but not for the 17C vs. 23C $(b=-0.10, S E$ $=0.22, t=-0.49)$, 23C vs. 29C ( $b=-0.33, S E=0.23, t=-1.45)$, or 29C vs. NW $(b=0.30, S E=0.22, t=1.38)$ contrasts. The effect of reading speed was significant $(b=2.28, S E=0.30, t=7.62)$. The window size $\times$ reading speed interactions were not significant for any contrast (all $|t s|<1.62$ ), indicating that number of forward fixations continued to drop with increasing window size up to the 17C window for both the EFL groups, with overall more forward fixations for slower than faster EFL readers.

For the L1 readers, the effects of window size were significant for the 5C vs. $11 \mathrm{C}$ ( $b=-4.79, S E=0.32, t=$ $-14.94), 11 \mathrm{C}$ vs. $17 \mathrm{C}(b=-1.43, S E=0.19, t=-7.61), 17 \mathrm{C}$ vs. $23 \mathrm{C}(b=-0.80, S E=0.14, t=-5.83), 23 \mathrm{C}$ vs. $29 \mathrm{C}(b=-0.44, \mathrm{SE}=0.13, t=-3.43)$, and $29 \mathrm{C}$ vs. NW $(b=0.38, S E=0.15, t=2.60)$ contrasts, indicating that numbers of forward fixations decreased with increasing window size up to the $29 \mathrm{C}$ condition.

\section{Discussion}

The current study utilized the GCMW paradigm to compare perceptual span size between EFL and L1-English readers and tested whether faster EFL readers had a larger perceptual span than slower EFL readers. Based on previous studies indicating that perceptual span is modulated by foveal load (e.g., Henderson \& Ferreira, 1990) and readers' reading speed (Rayner et al., 2010), we predicted that there would be differences between the perceptual spans of EFL and L1 readers, as well as between faster and slower EFL readers.

For the comparison between EFL and L1 readers, based on reading rates, L1 readers had a perceptual span extending 14 characters to the right of the fixation, replicating the findings of Rayner (1986) and other previous studies. In contrast, as predicted, the EFL participants showed a smaller perceptual span, which roughly equaled to eight characters to the right of fixation, indicating a six-character difference between the sizes of perceptual span of native English readers and Japanese learners of English. Although the results for average forward saccade length revealed that EFL readers were sensitive to increased parafoveal information beyond eight characters to the right of fixation, the increase was not strong enough to elicit a substantial increase in reading rate. Hence, based on the fact that the average word length used in our study was 4.2 characters, our data suggest that Japanese EFL readers generally can preprocess parafoveal information from only one upcoming word during a fixation, in contrast to L1-English readers whose perceptual span can extend to two upcoming words (Rayner, 1986; Rayner et al., 2009; Schotter et al., 2012).

Regarding reading speed among the EFL readers, the facilitating effects of increasing window size were larger for faster EFL reader for the $5 \mathrm{C}$ vs. $11 \mathrm{C}$ and $11 \mathrm{C}$ vs. $17 \mathrm{C}$ contrasts. This indicates that the facilitating effect from additional parafoveal information in the same area of the text is larger for faster EFL readers compared to slower EFL readers. These results are in line with previous findings that the perceptual span is a function of reading speed (e.g., Rayner et al., 2010), and support the findings of Yamashita and Ichikawa (2010) that more fluent EFL readers pay more attention to the upcoming word than do less fluent EFL readers.

However, we did not identify any differences in the overall sizes of the perceptual span between the two EFL groups. One explanation is that the difference in reading rate between the two EFL groups was not large enough to evoke a reading speed effect. Another explanation is that other factors, such as L2 proficiency or other reading components such as spelling skills (Veldre \& Andrews, 2014), might account for the difference in the size of the perceptual span among EFL readers. A third explanation is that EFL readers may choose a more cautious strategy by paying more attention to every word. As suggested by Mikulecky (1990), L2 readers tend to feel more secure by focusing on the meaning of every word in order to enhance text comprehension, regardless of their L2 proficiency and reading skill. In the current study, faster EFL readers were highly proficient EFL learners who had a mean reading rate of 174 WPM, which exceeded the reading rates of the second graders reported in Rayner (1986), who had a mean reading rate of around 100 WPM, albeit having a smaller perceptual span. Besides, the experimental sentences used in the current study can be considered easy even for EFL readers (i.e., basic words embedded in simple sentences) while the average word lengths, as well as the eye movement data for adult L1-English readers were highly comparable across the two studies. These make such a strategy account (see also Rayner et al., 2009; Wotschack \& Kliegl, 2012) a probable candidate for explaining the relatively small perceptual span, even among highly proficient EFL readers. Nevertheless, this notion needs to be refined, with further experiments that relate reading strategies and affective factors to eye movements during reading.

One limitation of the current study is that we did not examine the perceptual span to the left of fixation with the symmetrical windows used in the current experimental design. As reported by Apel, Henderson, and Ferreira (2012), it is possible that the perceptual span stretches further to the left of fixation when readers are about to 
make a regression. As the present data revealed that EFL readers tended to make more regressions than L1 readers (3.4 vs. 1.6 regressions per sentence in the NW condition on average) because of more reading difficulties, suggesting that EFL readers may have a more symmetric perceptual span, compared to L1 readers (see also Rayner et al., 2009, for the perceptual span among older L1 readers). The perceptual span to the left of fixation among L2 readers requires further investigation.

To conclude, we demonstrated how parafoveal information in the perceptual span facilitated EFL reading via higher reading rates with increasing window size in the GCMW paradigm. However, the perceptual span of EFL readers is smaller than that of L1 readers, revealing a difference in the allocation of attention between EFL and L1 reading. Faster EFL readers tend to make use of more parafoveal information than slower EFL readers do. Future research needs to shed light on the reading components, reading strategy and the higher tendency of making regressions among EFL readers in relation to the perceptual span during L2 reading.

\section{Acknowledgements}

This research was supported by a Grant-in-Aid for Young Scientists (B) (No. 80648262) to the first author and a Grant-in-Aid for Scientific Research (B) (No. 24320105) to the second author from the Japan Society for the Promotion of Science (JSPS).

\section{References}

Apel, J. K., Henderson, J. M., \& Ferreira, F. (2012). Targeting Regressions: Do Readers Pay Attention to the Left? Psychonomic Bulletin \& Review, 19, 1108-1113. http://dx.doi.org/10.3758/s13423-012-0291-1

Ashby, J., Yang, J., Evans, K. H. C., \& Rayner, K. (2012). Eye Movements and the Perceptual Span in Silent and Oral Reading. Attention, Perception \& Psychophysics, 74, 634-640. http://dx.doi.org/10.3758/s13414-012-0277-0

Baayen, R. H. (2008). Analyzing Linguistic Data: A Practical Introduction to Statistics. Cambridge: Cambridge University Press. http://dx.doi.org/10.1017/CBO9780511801686

Baayen, R. H., Davidson, D. J., \& Bates, D. M. (2008). Mixed-Effects Modeling with Crossed Random Effects for Subjects and Items. Journal of Memory and Language, 59, 390-412. http://dx.doi.org/10.1016/j.jml.2007.12.005

Bates, D., Maechler, M., \& Bolker, B. (2012). lme4: Linear Mixed-Effects Models Using S4 Classes (R Package Version 0.999999-0). http://cran.r-project.org/web/packages/lme4/index.html

Dubin, F., \& Bycina, D. (1991). Academic Reading and the ESL/EFL Teacher. In M. Celce-Murcia (Ed.), Teaching English as a Second or Foreign Language (2nd ed., pp. 195-215). New York: Newbury House.

Favreau, M., \& Segalowitz, N. S. (1982). Second Language Reading in Fluent Bilinguals. Applied Psycholinguistics, 3 , 329-341. http://dx.doi.org/10.1017/S0142716400004264

Häikiö, T., Bertram, R., Hyönä, J., \& Niemi, P. (2009). Development of the Letter Identity Span in Reading: Evidence from the Eye Movement Moving Window Paradigm. Journal of Experimental Child Psychology, 102, 167-181. http://dx.doi.org/10.1016/j.jecp.2008.04.002

Henderson, J. M., \& Ferreira, F. (1990). Effects of Foveal Processing Difficulty on the Perceptual Span in Reading: Implications for Attention and Eye Movement Control. Journal of Experimental Psychology: Learning, Memory, and Cognition, 16, 417-429. http://dx.doi.org/10.1037/0278-7393.16.3.417

Hirai, A. (1999). The Relationship between Listening and Reading Rates of Japanese EFL Learners. The Modern Language Journal, 83, 367-384. http://dx.doi.org/10.1111/0026-7902.00028

JACET Committee of Basic Words Revision (Ed.). (2003). JACET List of 8000 Basic Words: JACET 8000. Tokyo: JACET.

Jordan, T. J., Almabruk, A. A. A., Gadalla, E. M., McGowan, V. A., White, S. J., Abedipour, L., \& Paterson, K. B. (2014). Reading Direction and the Central Perceptual Span: Evidence from Arabic and English. Psychonomic Bulletin \& Review, 21, 505-511. http://dx.doi.org/10.3758/s13423-013-0510-4

McConkie, G. W., \& Rayner, K. (1975). The Span of the Effective Stimulus during a Fixation in Reading. Perception \& Psychophysics, 17, 578-586. http://dx.doi.org/10.3758/BF03203972

Miellet, S., O’Donnell, P. J., \& Sereno, S. C. (2009). Parafoveal Magnification: Visual Acuity Does Not Modulate the Perceptual Span in Reading. Psychological Science, 20, 721-728. http://dx.doi.org/10.1111/j.1467-9280.2009.02364.x

Mikulecky, B. S. (1990). A Short Course in Teaching Reading Skills. New York: Addison-Wesley.

Osaka, N., \& Osaka, M. (2002). Individual Differences in Working Memory during Reading with and without Parafoveal Information: A Moving-Window Study. The American Journal of Psychology, 115, 501-513. http://dx.doi.org/10.2307/1423525 
Paterson, K. B., McGowan, V. A., White, S. J., Malik, S., Abedipour, L., \& Jordan, T. R. (2014). Reading Direction and the Central Perceptual Span in Urdu and English. PLoS ONE, 9, e88358. http://dx.doi.org/10.1371/journal.pone.0088358

Plummer, P., \& Rayner, K. (2012). Effects of Parafoveal Word Length and Orthographic Features on Initial Fixation Landing Positions in Reading. Attention, Perception \& Psychophysics, 74, 950-963. http://dx.doi.org/10.3758/s13414-012-0286-z

Pollatsek, A., Bolozky, S., Well, A. D., \& Rayner, K. (1981). Asymmetries in the Perceptual Span for Israeli Readers. Brain and Language, 14, 174-180. http://dx.doi.org/10.1016/0093-934X(81)90073-0

R Development Core Team (2013). R: A Language and Environment for Statistical Computing. Vienna: R Foundation for Statistical Computing. http://www.R-project.org

Rayner, K. (1986). Eye Movements and the Perceptual Span in Beginning and Skilled Readers. Journal of Experimental Child Psychology, 41, 211-236. http://dx.doi.org/10.1016/0022-0965(86)90037-8

Rayner, K. (1998). Eye Movements in Reading and Information Processing: 20 Years of Research. Psychological Bulletin, 124, 372-422. http://dx.doi.org/10.1037/0033-2909.124.3.372

Rayner, K. (2009). Eye Movements and Attention in Reading, Scene Perception, and Visual Search. Quarterly Journal of Experimental Psychology, 62, 1457-1506. http://dx.doi.org/10.1080/17470210902816461

Rayner, K., Castelhano, M. S., \& Yang, J. (2009). Eye Movements and the Perceptual Span in Older and Younger Readers. Psychology \& Aging, 24, 755-760. http://dx.doi.org/10.1037/a0014300

Rayner, K., Liversedge, S. P., \& White, S. J. (2006). Eye Movements When Reading Disappearing Text: The Importance of the Word to the Right of Fixation. Vision Research, 46, 310-323. http://dx.doi.org/10.1016/j.visres.2005.06.018

Rayner, K., Pollatsek, A., Ashby, J., \& Clifton, C. (2012). The Psychology of Reading. New York: Psychology Press.

Rayner, K., Slattery, T. J., \& Bélanger, N. N. (2010). Eye Movements, the Perceptual Span, and Reading Speed. Psychonomic Bulletin \& Review, 17, 834-839. http://dx.doi.org/10.3758/PBR.17.6.834

Roberts, L., \& Siyanova-Chanturia, A. (2013). Using Eye-Tracking to Investigate Topics in L2 Acquisition and L2 Processing. Studies in Second Language Acquisition, 35, 213-235. http://dx.doi.org/10.1017/S0272263112000861

Schotter, E. R., Angele, B., \& Rayner, K. (2012). Parafoveal Processing in Reading. Attention, Perception \& Psychophysics, 74, 5-35. http://dx.doi.org/10.3758/s13414-011-0219-2

Smith, F. (1988). Understanding Reading (4th ed.). Mahwah, NJ: Lawrence Earlbaum Associate.

Taguchi, E., \& Gorsuch, G. (2002). Transfer Effects of Repeated EFL Reading on Reading New Passages: A Preliminary Investigation. Reading in a Foreign Language, 14, 43-65.

Veldre, A., \& Andrews, S. (2014). Lexical Quality and Eye Movements: Individual Differences in the Perceptual Span of Skilled Adult Readers. Quarterly Journal of Experimental Psychology, 67, 703-727. http://dx.doi.org/10.1080/17470218.2013.826258

Venables, W. N., \& Ripley, B. D. (2002). Modern Applied Statistics with S (4th ed.). New York: Springer. http://dx.doi.org/10.1007/978-0-387-21706-2

Whitford, V., O’Driscoll, G. A., Pack, C., Joober, R., Malla, A., \& Titone, D. (2013). Reading Impairments in Schizophrenia Relate to Individual Differences in Phonological Processing and Oculomotor Control: Evidence from a Gaze-Contingent Moving Window Paradigm. Journal of Experimental Psychology: General, 142, 57-75. http://dx.doi.org/10.1037/a0028062

Wotschack, C., \& Kliegl, R. (2013). Reading Strategy Modulates Parafoveal-on-Foveal Effects in Sentence Reading. Quarterly Journal of Experimental Psychology, 66, 548-562. http://dx.doi.org/10.1080/17470218.2011.625094

Yamashita, J., \& Ichikawa, S. (2010). Examining Reading Fluency in a Foreign Language: Effects of Text Segmentation on L2 Readers. Reading in a Foreign Language, 22, 263-283. 
Scientific Research Publishing (SCIRP) is one of the largest Open Access journal publishers. It is currently publishing more than 200 open access, online, peer-reviewed journals covering a wide range of academic disciplines. SCIRP serves the worldwide academic communities and contributes to the progress and application of science with its publication.

Other selected journals from SCIRP are listed as below. Submit your manuscript to us via either submit@scirp.org or Online Submission Portal.
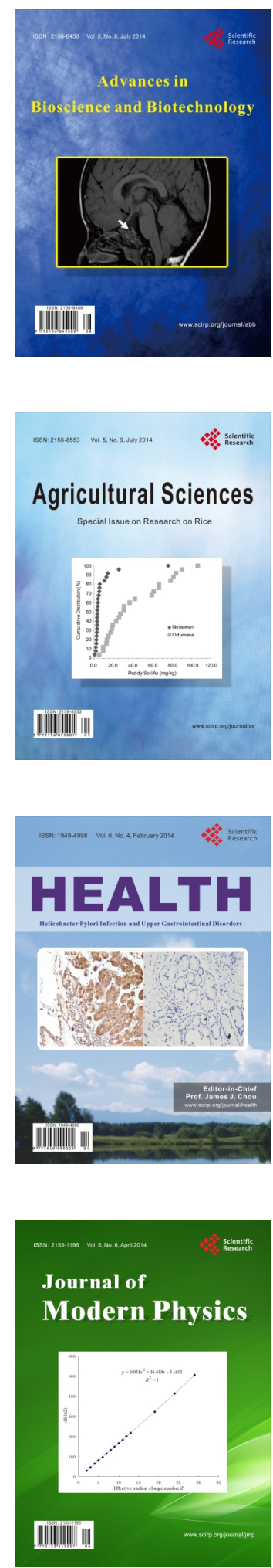
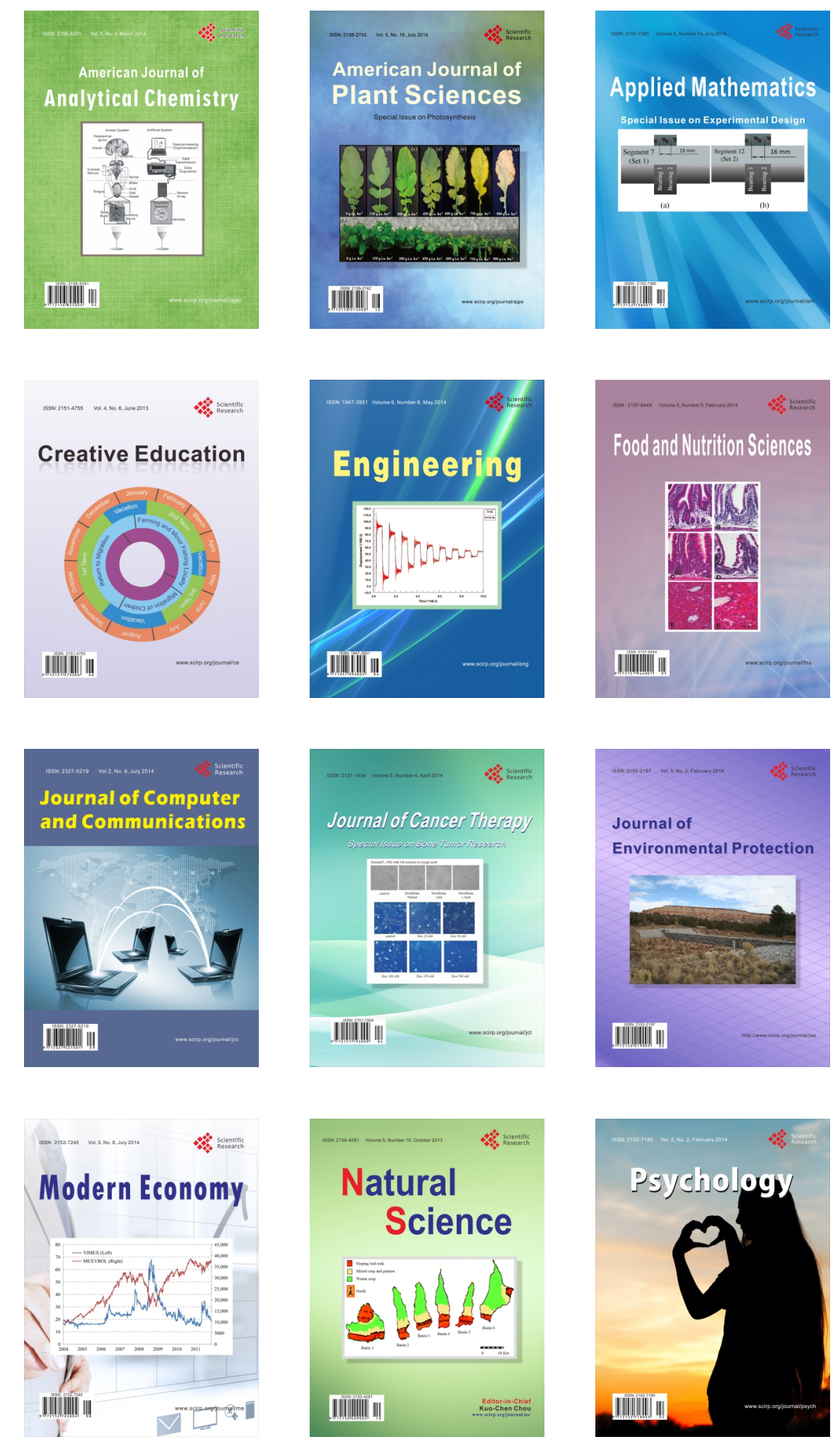